\title{
Relationship of Inter-Arm Systolic Blood Pressure Difference with Subclavian Artery Stenosis and Vertebral Artery Stenosis in Patients Undergoing Carotid Endarterectomy
}

Serkan Burç Deşer ${ }^{1}$, MD; Semih Murat Yucel' ${ }^{1}$, MD; Mustafa Kemal Demirag ${ }^{1}$, MD; Fersat Kolbakir ${ }^{1}$, MD; Hasan Tahsin Keceligil ${ }^{1}, \mathrm{MD}$

\section{Abstract}

Introduction: The aim of this study was to examine the association of inter-arm systolic blood pressure difference (IASBPD) with carotid artery stenosis, subclavian artery stenosis and vertebral artery stenosis in patients who underwent carotid endarterectomy.

Methods: A total of 141 patients (29 females, 112 males; mean age $71.2 \pm 10.4$ years; range 47 to 92 years) who underwent carotid endarterectomy between September 2010 and December 2017 were retrospectively evaluated. We classified patients into four groups according to the IASBPD $10 \mathrm{mmHg}, \geq 10 \mathrm{~mm} \mathrm{Hg}, \geq$ $20 \mathrm{mmHg}$ and $\geq 30 \mathrm{mmHg}$. The stenosis of both subclavian and vertebral arteries was considered as $\geq \mathbf{5 0} \%$.

Results: Of the 141 patients, 44 (31.2\%) had $\geq 10 \mathrm{mmHg}, 29$ $(20.5 \%) \mathrm{had} \geq 20 \mathrm{mmHg}$ and $4(2.8 \%)$ had $\geq 30 \mathrm{mmHg}$ of IASBPD. 26 patients $(18.4 \%)$ were diagnosed with significant subclavian artery stenosis and $18(69.2 \%)$ of them had more than $20 \mathrm{mmHg}$ of IASBPD. Of the 29 patients with IASBPD $\geq 20 \mathrm{mmHg}, 19$ patients $(65.5 \%)$ had a significant subclavian artery stenosis. We found a significant correlation between preoperative symptoms and subclavian artery stenosis $(P=0.018)$ and overall perioperative stroke was seen more frequently in patients with subclavian artery stenosis $(P=0.041)$. A significant positive correlation was observed between vertebral artery stenosis and subclavian artery stenosis $(P=0.01)$.

Conclusion: Patients who were diagnosed with both subclavian artery stenosis and IASBPD ( $\geq 20 \mathrm{mmHg}$ ) had a higher risk of postoperative stroke and death, had higher total cholesterol, LDL-C, blood creatinine level, and were more symptomatic.

Keywords: Subclavian Steal Syndrome. Carotid Stenosis. Blood Pressure Determination/Methods. Carotid Endarterectomy. Systole.

\begin{tabular}{llll}
\hline \multicolumn{2}{l}{ Abbreviations, acronyms \& symbols } & & \\
\hline CEA & $=$ carotid endarterectomy & ICU & = Intensive care unit \\
ESC & $=$ European Society of Cardiology & IQR & $=$ Interquartile range \\
ESH & $=$ European Society of Hypertension & LDL-C & $=$ Low density lipoprotein cholesterol \\
FT3 & $=$ Free T3 & NASCET & $=$ North American Symptomatic Carotid Surgery Trial \\
FT4 & $=$ Free T4 & RR & $=$ Relative risk \\
HB & $=$ Hemoglobin & SAS & $=$ Subclavian artery stenosis \\
HDL-C & $=$ High density lipoprotein cholesterol & SD & $=$ Standard deviation \\
IASBPD & $=$ Inter-arm systolic blood pressure difference & SPSS & $=$ Statistical Package for the Social Sciences \\
ICA & $=$ Internal carotid artery & TSH & $=$ Thyroid-stimulating hormone
\end{tabular}

'Department of Cardiovascular Surgery, School of Medicine, Ondokuz Mayis University, Samsun, Turkey.

This study was carried out at the Department of Cardiovascular Surgery, School of Medicine, Ondokuz Mayis University, Samsun, Turkey.
Corresponding Author:

Serkan Burç Deşer

iD) http://orcid.org/0000-0001-9490-928X

Ondokuz Mayis Universitesi, Tıp Fakültesi, Kalp ve Damar Cerrahisi Ana Bilim Dalı, Atakum, 55139, Samsun, Turkey

E-mail: sbd983@yahoo.com 


\section{INTRODUCTION}

An increased inter-arm systolic blood pressure difference (IASBPD) is usually considered as $\geq 10 \mathrm{mmHg}$, and the reported prevalence of the population ranges between 3,6\% and $9.4 \% \%^{[1-3]}$. IASBPD over $10 \mathrm{mmHg}$ of is usually associated with subclavian artery stenosis, cerebrovascular disease, stroke, cardiovascular morbidity and mortality, atherosclerosis and left ventricular hypertrophy ${ }^{[1-3]}$. Additionally, IASBPD over $15 \mathrm{mmHg}$ constitutes a 1,6 fold risk of cardiovascular morbidity and mortality ${ }^{[4-11]}$. Perioperative uncontrolled hypertension is observed in 13$23 \%$ of patients undergoing carotid endarterectomy (CEA) and associated with perioperative stroke and death ${ }^{[12,13]}$. For this reason, being aware of IASBPD is essential for the appropriate treatment of perioperative hypertension, especially in patients who underwent carotid endarterectomy ${ }^{[14]}$. The aim of this study was to examine the prevalence, association and outcomes of IASBPD, subclavian artery stenosis and vertebral artery stenosis in patients undergoing carotid endarterectomy.

\section{METHODS}

One hundred and forty-one patients (29 females, 112 males; mean age $71.2 \pm 10.4$ years; range 47 to 92 years) who underwent carotid endarterectomy between September 2010 and December 2017 were retrospectively included in this historic prospective study. Treatment indication for symptomatic patients was $\geq 50 \%$ stenosis, and for asymptomatic patients was $\geq 70 \%$ stenosis of the internal carotid artery, according to the North American Symptomatic Carotid Surgery Trial (NASCET) criteria $^{[15]}$. All demographic and clinical datas of the patients were retrieved from the hospital database. Six patients with combined CEA with coronary artery bypass grafting surgery and five patients with incomplete data were excluded from this study. Systolic and diastolic blood pressures were measured noninvasively at the time of admission and invasively monitored during the surgery and after the surgery in the intensive care unit. We divided patients into four groups according to the IASBPD as; $<10 \mathrm{mmHg}_{1} \geq 10 \mathrm{~mm} \mathrm{Hg}, \geq 20 \mathrm{mmHg}$ and $\geq 30 \mathrm{mmHg}^{[16]}$. Furthermore, patients were divided into another two groups with respect to significant stenosis of the subclavian artery $(\geq$ $50 \%)$ and the vertebral artery $(\geq 50 \%)^{[17]}$.

The internal carotid artery stenosis was initially diagnosed with color doppler ultrasonography and then the stenosis of carotid, subclavian and vertebral arteries were proven by computed tomography angiography, according to the NASCET criteria ${ }^{[15]}$. Additionally, routine transthoracic echocardiographic was performed on all patients in order to decide preoperative coronary angiography according to left ventricle ejection fraction and motion disorder of left ventricle wall. Patients' initial symptoms and physical examination, risk factors, laboratory analysis, perioperative complications, length of intensive care unit/in-hospital stay were analyzed. Conventional longitudinal endarterectomy with dacron or saphenous patch closure or modified eversion endarterectomy techniques were performed to all patients. Perioperative major neurological complications were considered as hemiplegia, hemiparesis, transient ischemic attack, and cerebral hyperperfusion syndrome. All patients undergoing surgery were under single antiplatelet therapy (acetic salicylic acid $100 \mathrm{mg} /$ day or clopidogrel $75 \mathrm{mg} /$ day) and continued with a single or dual antiplatelet therapy throughout their life, and low molecular weight heparin was administered for 3 days after the surgery. Cranial computed tomography scan, diffusion-weighted magnetic resonance imaging and carotid color doppler ultrasonography were performed in case of postoperative stroke.

The regional ethical committee approved the study (OMU KAEK 2017/353). The study was carried out in accordance with the Helsinki Declaration principles.

\section{Statistical Analysis}

The Statistical Package for the Social Sciences Windows Version 21 (SPSS Inc, Chicago, IL, USA) was used to compare the datas. The Kolmogorov-Smirnov test was used to analyze normally distributed continuous variables. Categorical variables were presented in percentages and frequencies. Continuous variables were presented as the mean \pm standard deviation (SD). Independent sample t-tests were used to compare the means of dependent groups. The continuous variables were compared using the t-test and the Mann-Whitney $U$ test. The categorical datas were tested with the chi-square test or Fisher's exact test. A $P$-value of $<0.05$ was considered statistically significant.

\section{RESULTS}

Of the 163 patients, perioperative blood pressure measurement data were available in 141 patients. The mean inter-arm systolic blood pressure difference was $11,23 \mathrm{~mm} \mathrm{Hg}$ (range 0-40 mm Hg). 44 patients (31.2\%) had an IASBPD $\geq 10$ $\mathrm{mmHg}, 29$ patients (20.5\%) had an IASBPD $\geq 20 \mathrm{mmHg}$, and $4(2.8 \%)$ patients had an IASBPD of $\geq 30 \mathrm{mmHg}$, while IASBPD was detected lower than $10 \mathrm{mmHg}$ in 97 patients (68.7\%). Table 1 summarizes the baseline characteristics of patients with IASBPD over $20 \mathrm{mmHg}$ and under $20 \mathrm{mmHg}$. Male gender was not associated with over $20 \mathrm{~mm} \mathrm{Hg}$ of IASBPD ( $P=0.89)$ and no correlation was detected between IASBPD and left or right internal carotid artery stenosis ( $P=0.63, P=0.78$, respectively) and treated internal carotid artery site $(P=0.24)$. However, we found a significant correlation between patients with IASBPD over 20 $\mathrm{mmHg}$ and ipsilateral subclavian artery stenosis $(P=0.009)$.

Of the 141 patients, 26 patients (18.4\%) were diagnosed with significant subclavian artery stenosis, while no significant stenosis was detected in 115 patients (81.6\%). 5 patients (3.5\%) had bilateral subclavian artery stenosis. Of the 29 patients with IASBPD $\geq 20 \mathrm{mmHg}, 19$ patients (65.5\%) had a significant subclavian artery stenosis $(P=0.001)$. Of the 26 patients with significant subclavian artery stenosis, 18 patients (69.2\%) had more than $20 \mathrm{mmHg}$ of IASBPD ( $P=0.001)$ and no IASBPD was detected in 5 patients (19.2\%). 47 patients (29\%) (15 patients with subclavian artery stenosis, 32 patients without subclavian artery stenosis) were symptomatic. A significant correlation was found between preoperative symptoms and subclavian artery stenosis $(P=0.018)$, in other words, patients with subclavian artery stenosis were more symptomatic. The mean IASBPD in patients with subclavian artery stenosis was $20.5 \pm 5.3 \mathrm{~mm} \mathrm{Hg}$ and the mean IASBPD in 
Table 1. Preoperative comparison of patients with Inter-arm systolic blood pressure difference (IASBPD) more than $20 \mathrm{mmHg}$ and patients with IASBPD less than $20 \mathrm{mmHg}$ who underwent carotid endarterectomy.

\begin{tabular}{|c|c|c|c|c|c|c|c|}
\hline & \multicolumn{3}{|c|}{$\begin{array}{l}\text { Patients with IASBPD } \geq 20 \mathrm{mmHg} \\
\qquad(\mathrm{n}=29)\end{array}$} & \multicolumn{3}{|c|}{$\begin{array}{l}\text { Patients with IASBPD }<20 \mathrm{mmHg} \\
\qquad(\mathrm{n}=112)\end{array}$} & \multirow[t]{2}{*}{$P$} \\
\hline & $\mathbf{n}$ & $\%$ & Mean \pm SD & $\mathbf{n}$ & $\%$ & Mean \pm SD & \\
\hline \multicolumn{8}{|l|}{ Gender } \\
\hline Male & 23 & 79.3 & & 90 & 80.3 & & 0.89 \\
\hline \multicolumn{8}{|l|}{ Surgical Side } \\
\hline Right & 17 & 58.6 & & 67 & 59.8 & & 0.90 \\
\hline \multicolumn{8}{|l|}{ Higher systolic blood pressure side } \\
\hline Right arm & 15 & 51.7 & & 63 & 56.2 & & 0.66 \\
\hline Left arm & 4 & 13.7 & & 23 & 20.5 & & 0.41 \\
\hline Symptomatic & 5 & 17.2 & & 23 & 20.5 & & 0.69 \\
\hline Asymptomatic & 24 & 82.8 & & 89 & 79.5 & & 0.69 \\
\hline Body mass index & & & $26.7 \pm 3.7$ & & & $26.9 \pm 4.3$ & 0.81 \\
\hline Current smoking & 5 & 17.2 & & 24 & 21.4 & & 0.61 \\
\hline Diabetes mellitus & 19 & 65.5 & & 69 & 61.6 & & 0.69 \\
\hline Hypertension & 17 & 58.6 & & 60 & 53.5 & & 0.62 \\
\hline Coronary artery disease & 8 & 27.5 & & 34 & 30.3 & & 0.77 \\
\hline Peripheral artery disease & 4 & 13.7 & & 21 & 18.7 & & 0.78 \\
\hline Chronic obstructive pulmonary disease & 3 & 10.3 & & 20 & 17.8 & & 0.40 \\
\hline Lipid lowering therapy & 9 & 31 & & 30 & 26.7 & & 0.64 \\
\hline Antithrombotic therapy & 12 & 41.3 & & 45 & 40.1 & & 0.90 \\
\hline
\end{tabular}

IASBPD=inter-arm systolic blood pressure difference; SD=standard deviation

patients without subclavian artery stenosis was $8.5 \pm 3.1 \mathrm{~mm} \mathrm{Hg}$ $(P=0.01)$. Patients with subclavian artery stenosis had higher total cholesterol level $(P=0.01)$, higher $L D L-C$ level $(P=0.015)$, higher blood creatinine level $(P=0.017)$, higher free T3 level $(P=0.022)$, higher postoperative-day 1 systolic blood pressure $(P=0.023)$, were older $(P=0.045)$, and ICU/overall in-hospital stay differences were longer ( $P=0.01$ and $P=0.01$, respectively). Additionally, no systolic blood pressure difference was noted in terms of subclavian artery stenosis $(149,8 \mathrm{mmHg}$ vs. $146,4 \mathrm{mmHg}, P=0.78)$. Table 2 compares patients with subclavian artery stenosis and without who undergoing carotid endarterectomy.

The median follow-up time was 4,6 years (IQR, 2.0-5.0, maximum 8 years). In 80 patients, (56.7\%) right arm systolic blood pressure was higher than the left arm while, in 29 patients (20.6\%) left arm systolic blood pressure was higher, and 32 patients (22.7\%) had no systolic blood pressure difference between arms. 31 patients (21.9\%) had vertebral artery stenosis (15 right, 10 left and 6 bilateral). Of the 26 patients with subclavian artery stenosis, 16 patients (61.5\%) were accompanied with vertebral artery stenosis $(P=0.01)$. However, no significant correlation was found between vertebral artery stenosis and, stroke and carotid artery stenosis ( $P=0.12$ and $P=0.23$, respectively).
A perioperative stroke had occurred in 5 patients (3.5\%). The most common reason of perioperative stroke was comprising thrombo-embolic event in 2 patients (1.4\%), cerebral hyperperfusion syndrome in 2 patients (1.4\%) and internal carotid artery occlusion in 1 patient (0.7\%). 4 patients (2.8\%) were diagnosed with both subclavian artery stenosis and IASBPD ( $\geq 20 \mathrm{mmHg}$ ) $(P=0.04)$ and 1 patient (1.4\%) neither had subclavian artery stenosis nor IASBPD. Post operative death occurred in 3 patients (2.1\%) with both subclavian artery stenosis and IASBPD ( $P=0.0057, P=0.008$, respectively), while no perioperative myocardial infarction occurred due to our strict cardiac examination.

\section{Discussion}

This historic prospective study demonstrates that patients who were diagnosed with both subclavian artery stenosis and IASBPD ( $\geq 20 \mathrm{mmHg}$ ) had a higher risk of perioperative stroke and death, higher total cholesterol, LDL-C and blood creatinine level, and were more symptomatic. In addition, subclavian artery stenosis was associated with vertebral artery stenosis. To the best of our knowledge, this is the first study to evaluate the relationship 
Table 2. Comparison of patients with subclavian artery stenosis (SAS) and without SAS who underwent carotid endarterectomy.

\begin{tabular}{|c|c|c|c|c|c|c|c|}
\hline & \multicolumn{3}{|c|}{$\begin{array}{c}\begin{array}{c}\text { Patients with SAS } \\
(\mathrm{n}=26)\end{array} \\
\end{array}$} & \multicolumn{3}{|c|}{$\begin{array}{l}\text { Patients without SAS } \\
(n=115)\end{array}$} & \multirow[t]{2}{*}{$P$} \\
\hline & $\mathbf{n}$ & $\%$ & Mean \pm SD & $\mathbf{n}$ & $\%$ & Mean \pm SD & \\
\hline Age (year) & & & $73.6 \pm 4.6$ & & & $69.5 \pm 10.1$ & $0.045^{*}$ \\
\hline Symptomatic & 15 & 57.6 & & 32 & 27.8 & & $0.018^{*}$ \\
\hline HbA1c (NGSP) & & & $6.5 \pm 1.7$ & & & $6.4 \pm 1.4$ & 0.75 \\
\hline $\mathrm{Hb}(\mathrm{g} / \mathrm{dL})$ & & & $14.7 \pm 1.7$ & & & $14.9 \pm 1.5$ & 0.55 \\
\hline $\mathrm{Htc}(\%)$ & & & $43.8 \pm 4.6$ & & & $44.6 \pm 4.1$ & 0.38 \\
\hline Total cholesterol (mg/dL) & & & $226.4 \pm 16.94$ & & & $205.3 \pm 20.37$ & $0.01^{*}$ \\
\hline Triglycerides (mg/dL) & & & $152.2 \pm 75.2$ & & & $160.1 \pm 86.3$ & 0.66 \\
\hline $\mathrm{HDL}-\mathrm{C}(\mathrm{mg} / \mathrm{dL})$ & & & $41.6 \pm 11.9$ & & & $40.3 \pm 11.2$ & 0.59 \\
\hline LDL-C (mg/dL) & & & $164.56 \pm 32.4$ & & & $153.4 \pm 17.54$ & $0.015^{*}$ \\
\hline Blood creatinine (mg/dL) & & & $1.68 \pm 1.34$ & & & $1.23 \pm 0.72$ & $0.017^{*}$ \\
\hline fT3 $(\mathrm{pg} / \mathrm{mL})$ & & & $3.13 \pm 1.11$ & & & $2.7 \pm 0.79$ & $0.022^{*}$ \\
\hline fT4 (ng/dL) & & & $1.33 \pm 0.26$ & & & $1.4 \pm 0.45$ & 0.44 \\
\hline TSH (mlU/mL) & & & $1.7 \pm 1.4$ & & & $1.84 \pm 3.2$ & 0.82 \\
\hline ICU stay (days) & & & $11.2 \pm 7.5$ & & & $1.2 \pm 0.45$ & $0.01^{*}$ \\
\hline Overall in-hospital stay (days) & & & $28.2 \pm 18.3$ & & & $3.1 \pm 0.71$ & $0.01^{*}$ \\
\hline \multicolumn{8}{|l|}{ Perioperative stroke } \\
\hline Thrombo-embolic & 2 & & & - & & & $0.032^{*}$ \\
\hline Cerebral hyperperfusion syndrome & 2 & & & - & & & $0.032^{*}$ \\
\hline ICA occlusion & - & & & 1 & & & 1 \\
\hline Overall & 4 & & & 1 & & & $0.041^{*}$ \\
\hline
\end{tabular}

*Significant

fT3=free T3; $\mathrm{fT} 4=$ free T4; $\mathrm{Hb}=$ hemoglobin; $\mathrm{HDL}-\mathrm{C}=$ high density lipoprotein cholesterol; Htc=hematocrit; ICA=internal carotid artery; ICU=intensive care unit; LDL-C=Iow density lipoprotein cholesterol; SAS=Subclavian artery stenosis; SD=standard deviation; $\mathrm{TSH}=$ thyroid-stimulating hormone

between IASBPD and carotid artery stenosis, subclavian artery stenosis and vertebral artery stenosis in terms of perioperative outcomes in patients undergoing carotid endarterectomy.

Perioperative blood pressure disturbances are seen in $13-23 \%$ of patients undergoing carotid endarterectomy ${ }^{[13,18]}$. Thus, perioperative blood pressure measurement of both arms is essential to avoid mistaken blood pressure measurement, which may lead to perioperative stroke due to cerebral hyperperfusion syndrome in patients undergoing carotid endarterectomy ${ }^{[12,13,17,19,20]}$. The relation of subclavian artery stenosis and more than $20 \mathrm{mmHg}$ of IASBPD is already well established with a recent meta-analysis conducted by Cao et al. ${ }^{[2]}$, which supported this strong association (RR 8.8, 95\% Cl 3.6$21.2, P<0.01)$ and our findings were consistent with this previous study ( $P=0.009$ ). English et al. ${ }^{[20]}$ reported that the sensitivity and the specificity to detect the subclavian artery stenosis for more than $10 \mathrm{mmHg}$ of IASBPD was $65 \%$ and $85 \%$ while, $20 \mathrm{mmHg}$ of difference was 35\% and 94\%, respectively. Worthy of note, most of the previous studies considered a threshold value of $20 \mathrm{mmHg}^{[17,19]}$ thus we considered $20 \mathrm{mmHg}$ of IASBPD as a threshhold value.

Huibers et al. ${ }^{[17]}$ published a 182-patient, multicenter, randomized control trial where $20 \%$ of the patients had more than $15 \mathrm{mmHg}$ of IASBPD. Of those patients, 20\% of them were accompanying with subclavian or innominate artery stenosis, in patients undergoing carotid endarterectomy. In addition, Huibers et al. ${ }^{[17]}$ stated that $47.6 \%$ of patients with subclavian artery stenosis had more than $10 \mathrm{mmHg}$ of IASBPD while, 23.3\% of patients with more than $20 \mathrm{mmHg}$ of IASBPD had a significant subclavian artery stenosis. Our findings were higher than the previous study, where $69.2 \%$ of patients with subclavian artery stenosis had more than $20 \mathrm{mmHg}$ of IASBPD, while $65.5 \%$ of patients with more than $20 \mathrm{mmHg}$ of IASBPD had a significant subclavian artery stenosis. The incidence of both subclavian artery stenosis and more than $20 \mathrm{mmHg}$ of IASBPD was $94.7 \%{ }^{[18,19]}$. We concluded that these relatively high ratios depend on the 
routine measurement of both arm systolic blood pressure in our cardiovascular surgery clinic. In addition, computed tomography angiography was routinely performed to all patients diagnosed with severe stenosis by color doppler ultrasonography, and both subclavian and vertebral arteries were examined simultaneously.

Kranenburg et al. ${ }^{[19]}$ reported a strong relation with IASBPD and the carotid artery stenosis in patients with peripheral vascular diseases, whereas we did not note any correlation $(P=0.78)$. Besides that, no superiority was found for each arm systolic blood pressure in regard to outcomes ${ }^{[19]}$. In this context, our study demonstrated a similar manner with previous studies ${ }^{[17,19]}$, that no superiority of left and right arm systolic blood pressure was detected $(P=0.672)$.

Huibers et al. ${ }^{[17]}$ reported that the prevalence of patients with bilateral subclavian artery stenosis was 1\%. However, 3.5\% of patients (5 patients) had bilateral subclavian artery stenosis in our study. Of note, systolic blood pressure difference can not be detected between both arms in case of bilateral subclavian artery stenosis. Although, we did not find any relations between subclavian artery stenosis and carotid artery stenosis, it is interesting to note that, in the present study, a significant correlation was found between preoperative symptoms and subclavian artery stenosis $(P=0.018)$. In other words, the majority of symptomatic patients were diagnosed with subclavian artery stenosis at the same time. In addition, total cholesterol, LDL, blood creatinine level, fT3 level, postoperative day 1. systolic blood pressure was higher and ICU/overall in-hospital stay was longer in patients with subclavian artery stenosis, and patients were older. We thought that atherosclerosis was more advanced in those patients and significant disease was also present in all systemic arteries except carotid arteries. This mechanism might also explain why we found a higher ratio of subclavian artery stenosis in our study, contrary to Huibers et al. ${ }^{[17]}$. Therefore, in those patients, blood pressure should be measured in both arms and further examination should be performed in terms of subclavian artery stenosis.

In patients with carotid artery stenosis, aortic arches and branches are routinely examined, so an additional imaging modality is not required in the diagnosis of subclavian artery stenosis and vertebral artery stenosis without excessive radiation exposure to patients. In this study, the proportion of patients with IASBPD greater than $10 \mathrm{mmHg}$ was found to be relatively low (31.2\%) among all patients. When we increased the threshold level from $10 \mathrm{~mm} \mathrm{Hg}$ to $20 \mathrm{~mm} \mathrm{Hg}$, this rate decreases to $20.5 \%$ of patients.

We found a significant correlation between subclavian artery stenosis and vertebral artery stenosis, thus we re-evaluated patients in terms of preoperative vertebra-basilary system symptoms such as dizziness. However, no difference was found as expected in symptomatic patients. In addition, no subclavian artery occlusion, nor subclavian steal phenomenon were noted in any patient, although the rate of significant subclavian artery stenosis was found higher rather than previous studies ${ }^{[21]}$.

The relation between subclavian artery stenosis and atherosclerosis is obvious. In this current study, the perioperative stroke was seen more frequently in patients with subclavian artery stenosis $(P=0.041)$. This mechanism might also explain by cerebral hyperperfusion syndrome due to mistaken systolic blood pressure measurement or atherosclerosis level may be more advanced in those group of patients with a worse vascular structure $(P=0.032)$. In addition, Huibers et al. ${ }^{[21]}$ reported that IASBPD was existing in all patients who had a perioperative stroke due to cerebral hyperperfusion syndrome.

There are some limitations of our study. First, this study had a retrospective design. Second, the number of patients in our study may seem limited compared with other studies. Third, larger studies would be required to replicate our findings. Fourth, the power of some outcomes may have been reduced due to this single-center study. Fifth, IASBPD may change in subsequent years due to a relatively short follow-up period of 4.6 years. Sixth, as mentioned above, we thought that patients with subclavian artery stenosis had more severe atherosclerosis level; however, we did note any correlation with peripheral arterial disease, this issue should be focused on further prospective studies. Seventh, we did not compare patients with 20-30 mmHg of IASBPD and patients with more than $30 \mathrm{mmHg}$ of IASBPD, owing to a low volume of patients who had more than 30 $\mathrm{mmHg}$ of IASBPD. Strengths of this study include the measuring both arm blood pressures in all patients during admission and computed tomography angiography was performed to all patients. However, our results might need further validation in community-based cohorts.

\section{CONCLUSION}

Our findings in this single-center study suggest that measuring both arm blood pressure is a valuable clinical parameter during the in-hospital stay and careful attention should be paid to perioperative blood pressure, which may reduce the risk of procedural complications. A difference in IASBPD of $\geq 20 \mathrm{mmHg}$ had a significant correlation with both subclavian artery stenosis, and subclavian artery stenosis was associated with perioperative stroke, preoperative symptoms and vertebral artery stenosis. However, we could not conclude any correlation with carotid artery stenosis, and subclavian artery stenosis and IASBPD. Those groups of patients with more than 20 $\mathrm{mmHg}$ of IASBPD should definitely be investigated for subclavian artery stenosis.

\section{No financial support. \\ No conflict of interest.}

\begin{tabular}{|c|c|}
\hline \multicolumn{2}{|c|}{ Authors' roles \& responsibilities } \\
\hline SBD & $\begin{array}{l}\text { Design, analysis, writing; final approval of the version to } \\
\text { be published }\end{array}$ \\
\hline SMY & $\begin{array}{l}\text { Design, writing; final approval of the version to be } \\
\text { published }\end{array}$ \\
\hline MKD & Design; final approval of the version to be published \\
\hline FK & Analysis; final approval of the version to be published \\
\hline HTK & Analysis; final approval of the version to be published \\
\hline
\end{tabular}




\section{REFERENCES}

1. Clark CE, Taylor RS, Shore AC, Ukoumunne OC, Campbell JL. Association of a difference in systolic blood pressure between arms with vascular disease and mortality: a systematic review and meta-analysis. Lancet. 2012 Mar 10;379(9819):905-914. doi:10.1016/S0140-6736(11)61710-8. Erratum in: Lancet. 2012 Jul 21;380(9838):218.

2. Cao K, Xu J, Shangguan Q, Hu W, Li P, Cheng X, et al. Association of an inter-arm systolic blood pressure difference with all-cause and cardiovascular mortality: An updated meta-analysis of cohort studies. Int J Cardiol. 2015;189:211-9. doi:10.1016/j.ijcard.2015.04.079.

3. Su HM, Lin TH, Hsu PC, Chu CY, Lee WH, Chen SC, Lee CS, Voon WC, Lai WT, Sheu SH. Association of interarm systolic blood pressure difference with atherosclerosis and left ventricular hypertrophy. PLOS One. 2012;7(8):e41173. doi:10.1371/journal.pone.0041173.

4. Aboyans V, Criqui MH, McDermott MM, Allison MA, Denenberg JO, Shadman R, Fronek A. The vital prognosis of subclavian stenosis. J Am Coll Cardiol. 2007 Apr 10;49(14):1540-5.

5. Mancia G, Fagard R, Narkiewicz K, Redon J, Zanchetti A, Böhm M, et al. 2013 ESH/ESC Practice Guidelines for the Management of Arterial Hypertension. Blood Press. 2014 Feb;23(1):3-16. doi:10.3109/080370 51.2014.868629.

6. Singh S, Sethi A, Singh M, Khosla K, Grewal N, Khosla S. Simultaneously measured inter-arm and inter-leg systolic blood pressure differences and cardiovascular risk stratification: a systemic review and metaanalysis. J Am Soc Hypertens. 2015 Aug;9(8):640-650.e12. doi:10.1016/j. jash.2015.05.013.

7. Clark CE, Taylor RS, Shore AC, Campbell JL. The difference in blood pressure readings between arms and survival: primary care cohort study. BMJ. 2012 Mar 20;344:e1327. doi:10.1136/bmj.e1327.

8. Mehlsen J, Wiinberg N. Interarm difference in blood pressure: reproducibility and association with peripheral vascular disease. Int J Vasc Med. 2014;2014:841542. doi:10.1155/2014/841542.

9. Mancia G, De Backer G, Dominiczak A, Cifkova R, Fagard R, Germano G, et al. 2007 Guidelines for the management of arterial hypertension: The Task Force for the Management of Arterial Hypertension of the European Society of Hypertension (ESH) and of the European Society of Cardiology (ESC). Eur Heart J. 2007 Jun;28(12):1462-536.

10. Gaynor E, Brewer L, Mellon L, Hall P, Horgan F, Shelley E, et al. Interarm blood pressure difference in a post-stroke population. J Am Soc Hypertens. 2017 Sep;11(9):565-572.e5. doi:10.1016/j.jash.2017.06.008.

11. Clark CE, Steele AM, Taylor RS, Shore AC, Ukoumunne OC, Campbell JL. Interarm blood pressure difference in people with diabetes: measurement and vascular and mortality implications: a cohort study.
Diabetes Care. 2014 Jun;37(6):1613-20. doi: 10.2337/dc13-1576.

12. Altinbas A, Algra A, Brown MM, Featherstone RL, Kappelle LJ, de Borst GJ, et al. Effects of carotid endarterectomy or stenting on hemodynamic complications in the International Carotid Stenting Study: a randomized comparison. Int J Stroke. 2014 Apr;9(3):284-90. doi:10.1111/ijs.12089.

13. Tan TW, Eslami MH, Kalish JA, Eberhardt RT, Doros G, Goodney PP, et al. The need for treatment of hemodynamic instability following carotid endarterectomy is associated with increased perioperative and 1-year morbidity and mortality. J Vasc Surg. 2014 Jan;59(1):16-24. e1-2. doi:10.1016/j.jvs.2013.07.025.

14. North American Symptomatic Carotid Endarterectomy Trial Collaborators, Barnett HJM, Taylor DW, Haynes RB, Sackett DL, Peerless SJ, et al. Beneficial effect of carotid endarterectomy in symptomatic patients with high-grade carotid stenosis. N Engl J Med. 1991 Aug 15;325(7):445-53.

15. Moran AE, Odden MC, Thanataveerat A, Tzong KY, Rasmussen PW, Guzman D, et al. Cost-effectiveness of hypertension therapy according to 2014 guidelines. N Engl J Med. 2015 Jan 29;372(5):447-55. doi:10.1056/ NEJMsa1406751. Erratum in: N Engl J Med. 2015 Apr 23;372(17):1677.

16. Moran AE, Odden MC, Thanataveerat A, Tzong KY, Rasmussen PW, Guzman D, et al. Cost-effectiveness of hyper-tension therapy according to 2014 guidelines. N Engl J Med 2015;372:447-55.

17. Huibers A, Hendrikse J, Brown MM, Pegge SA, Arnold M, Moll FL, et al. Upper Extremity Blood Pressure Difference in Patients Undergoing Carotid Revascularisation. Eur JVasc Endovasc Surg. 2017 Feb;53(2):153157. doi:10.1016/j.ejvs.2016.11.023.

18. Park BD, Divinagracia T, Madej O, McPhelimy C, Piccirillo B, Dahn MS, et al. Predictors of clinically significant postprocedural hypotension after carotid endarterectomy and carotid angioplasty with stenting. J Vasc Surg. 2009 Sep;50(3):526-33. doi:10.1016/j.jvs.2009.05.005.

19. Kranenburg G, Spiering W, de Jong PA, Kappelle LJ, de Borst GJ, Cramer MJ, et al. Inter-arm systolic blood pressure differences, relations with future vascular events and mortality in patients with and without manifest vascular disease. Int J Cardiol. 2017 Oct 1;244:271-276. doi:10.1016/j.jicard.2017.06.044.

20. English JA, Carell ES, Guidera SA, Tripp HF. Angiographic prevalence and clinical predictors of left subclavian stenosis in patients undergoing diagnostic cardiac catheterization. Catheter Cardiovasc Interv. 2001 Sep;54(1):8-11.

21. Huibers A, Calvet D, Kennedy F, Czuriga-Kovács KR, Featherstone RL, Moll FL, et al. Mechanism of Procedural Stroke Following Carotid Endarterectomy or Carotid Artery Stenting Within the International Carotid Stenting Study (ICSS) Randomised Trial. Eur J Vasc EndovasC Surg. 2015 Sep;50(3):281-8. doi:10.1016/j.ejvs.2015.05.017. 